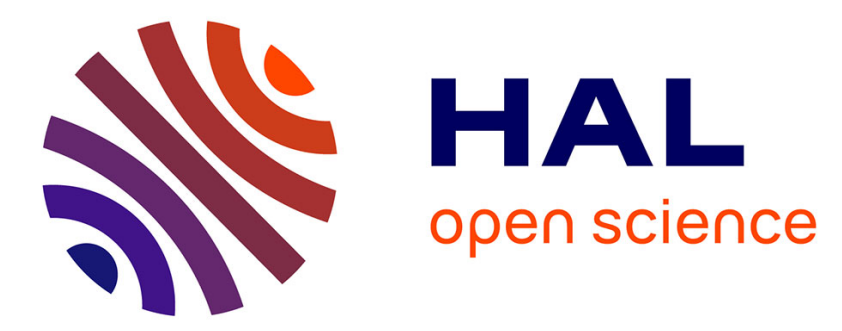

\title{
Glutamate transporter 1-expressing glia in the rat substantia nigra-Morphometric analysis and relationships to synapses
}

\author{
Jean-Pierre Kessler, Pascal Salin, Lydia Kerkerian-Le Goff
}

\section{To cite this version:}

Jean-Pierre Kessler, Pascal Salin, Lydia Kerkerian-Le Goff. Glutamate transporter 1-expressing glia in the rat substantia nigra-Morphometric analysis and relationships to synapses. Glia, 2020, 68 (10), pp.2028-2039. 10.1002/glia.23823 . hal-02518982

\section{HAL Id: hal-02518982 \\ https://hal.science/hal-02518982}

Submitted on 24 Nov 2020

HAL is a multi-disciplinary open access archive for the deposit and dissemination of scientific research documents, whether they are published or not. The documents may come from teaching and research institutions in France or abroad, or from public or private research centers.
L'archive ouverte pluridisciplinaire HAL, est destinée au dépôt et à la diffusion de documents scientifiques de niveau recherche, publiés ou non, émanant des établissements d'enseignement et de recherche français ou étrangers, des laboratoires publics ou privés. 
Title: Glutamate transporter 1-expressing glia in the rat substantia nigra - Morphometric analysis and relationships to synapses.

Authors: Jean-Pierre Kessler, Pascal Salin, Lydia Kerkerian-Le Goff

Aix Marseille Univ, CNRS, IBDM, Marseille, France.

Acknowledgments: This work was supported by the Centre National de la Recherche Scientifique (CNRS), Aix-marseille Université and the «Investments for the future» (France-BioImaging) grant No ANR--10--INBS--04--01b (to the imaging facilities of the IBDM). The IBDM is affiliated with MarseilleNeuroSchool, a graduate school supported by the A*MIDEX foundation and the "Investissements d'Avenir" program (nEURo*AMU, ANR-17-EURE-0029 grant). The authors especially thank the staffs of the IBDM optical and electron microscope imaging facilities for expert technical assistance.

Conflict of interest. The authors have no conflict of interest to declare.

Data availability statement: The data that support the findings of this study are available from the corresponding author upon reasonable request.

Word counts.

Total: 4289

Abstract: 245

Introduction: 621

Methods: 1069

Results: 1049

Discussion: 1288

Main Points:

- The rat substantia nigra contains a dense network of GLT1-expressing glial processes.

- Excitatory synapses are few and have limited glial coverage.

- The glial membrane to excitatory synapse ratio is high, suggesting efficient regulation of extracellular glutamate. 


\section{ABSTRACT}

Glial cells have a major role in protecting neurons against various forms of stress. Especially, astrocytes mediate the bulk of glutamate clearance in the brain via specific membrane transporters (GLAST and GLT1), thereby preventing the occurrence of excitotoxic events. Although glutamatemediated mechanisms are thought to contribute to nigral dopaminergic neuron degeneration in Parkinson's disease, detailed information on the organization of glia in the substantia nigra is still lacking. The present study was performed to provide quantitative information on the organization of astroglia and on the relationships between astrocytes and excitatory synapses in the rat substantia nigra. Using immunolabeling of GLT1 and confocal imaging, we found that the substantia nigra was filled with a dense meshwork of immunoreactive astrocyte processes. Stereological analysis performed on electron microscope images revealed that the density of immunoreactive astrocyte plasma membranes was substantial, close to $1 \mu \mathrm{m}^{2} / \mu \mathrm{m}^{3}$, in the substantia nigra neuropil, both in the pars compacta and the pars reticulata. Excitatory synapses had on average two thirds of their perimeters free from glia, a disposition that may favor transmitter spillover. The density of glutamatergic synapses, as quantified on confocal images by the simultaneous detection of bassoon and of vesicular glutamate transporter 1 or 2 , was very low $\left(0.01\right.$ and 0.025 per $\mu \mathrm{m}^{3}$ in the reticulata and compacta subdivisions, respectively). Thus the ratio of GLT1-expressing glial membrane surface to glutamatergic synapses was very high (40-100 $\mu^{2}{ }^{2}$, suggesting an efficient regulation of extracellular glutamate concentrations.

Keywords: substantia nigra, astrocytes, perisynaptic glia, glutamatergic synapses, electron microscopy, confocal microscopy. 


\section{INTRODUCTION}

The substantia nigra (SN) includes two main types of neurons: GABAergic neurons, which correspond to the output of the basal ganglia circuitry and send major projections to the thalamus, and dopaminergic neurons, which mainly project to the dorsal striatum. Nigral dopaminergic neurons have their cell bodies located in the pars compacta of the SN (SNc). Some of their dendrites extend in the neighboring pars reticulata $(\mathrm{SNr})$ where they are intermingled with cell bodies and dendrites of GABAergic nigral cells. The progressive loss of dopaminergic neurons located in the $\mathrm{SNc}$ is the hallmark of Parkinson's disease, a common neurodegenerative disease. Apart from few inherited cases, Parkinson's disease is thought to result from a variety of harmful events acting alone or in combination to induce programmed cell death in nigral dopaminergic neurons. These potential causative factors include oxidative stress, mitochondrial dysfunction, protein misfolding/aggregation, autophagy, neuro-inflammation and excitotoxicity (Teismann and Schulz 2004; Hirsch et al. 2013; Sulzer and Surmeyer 2013; Ambrosi et al. 2014).

Protoplasmic astrocytes, the type of astrocytes found in grey matter nuclei, play a key role in neuroprotection (Takuma et al. 2004). They do so not only by releasing factors and metabolic substrates required for the survival and the proper functioning of neurons, but also by removing potentially toxic agents from extracellular fluids. For instance, protoplasmic astrocytes help neurons fighting oxidative stress by supplying them with precursors required for the synthesis of the main neuronal antioxidant glutathione (Sagara et al, 1993; Dringen et al. 1999). Protoplasmic astrocytes also mediate the bulk of glutamate clearance in the brain. Glutamate, the main excitatory transmitter in the mammalian central nervous system, may induce neuronal damages if present in excessive ambient concentrations. Protoplasmic astrocytes express very high levels of specific plasma membranes transporters (GLAST and/or GLT1 depending on the brain region) that carry out the rapid removal of synaptically released glutamate from extracellular fluids, thereby preventing the occurrence of excitotoxic events (see Danbolt 2001 for review). The potential involvement of astrocytes in the pathogenesis of Parkinson disease has attracted much attention during the last decades. Several lines of evidence indicate that alterations in astrocyte functions may be involved in the neuro-degeneration of nigral dopaminergic cells during the course of the disease (reviewed in Hirsch 2000; Teismann and Schultz 2004; Rappold and Tieu 2010; Joe et al. 2018). Accordingly, the higher vulnerability of nigral dopaminergic neurons as compared to dopaminergic neurons in the ventral tegmental area has been linked to regional differences in astrocyte numbers and/or properties (Damier et al. 1993; Kostuc et al. 2018). In addition, some data point out impaired glutamate homeostasis as a key factor contributing to dopaminergic cell death, suggesting an important role of nigral astrocytes in protecting dopaminergic neurons against excitotoxicity. For 
instance, it has been shown that the programmed cell death of dopaminergic neurons in a chronic MPTP mouse model of Parkinson's disease occurs with increases in extracellular levels of glutamate (Meredith et al. 2009). Likewise, injection of the substrate inhibitor of glutamate transporters PDC in the SN triggers a progressive neurodegenerative process that preferentially affects dopaminergic neurons and recapitulates several features of Parkinson's disease (Assous et al. 2014).

Despite the presumably important role of astroglia in preventing dopaminergic cells neurodegeneration, very few data are currently available regarding its organization in the SN. The present study was designed to provide quantitative ultrastructural information on nigral astrocytes with emphasis on glia to synapses relationships. Using stereological methods, we determined the densities of glutamate transporter-expressing astroglial membranes and measured the average levels of glial ensheathment of nigral excitatory and inhibitory synapses. These data pertaining to astroglia glutamate uptake systems were completed by measurements of glutamatergic synapses densities in the $\mathrm{SNc}$ and the $\mathrm{SNr}$ in order to provide information on local glutamate release capacities.

\section{METHODS}

\section{Animals and tissue preparation}

Experiments were performed on 12-14 weeks old male Wistar rats $(n=5)$ in accordance with the European Communities Council Directive (2010/63/EU). Protocols were approved by the local ethical committee and conformed to the ethical guidelines of the French Ministry of Agriculture and Forests (Animal Health and Protection Veterinary Service). Animals were anesthetized with a mixture of ketamine $(50 \mathrm{mg} / \mathrm{kg})$ and xylazine $(15 \mathrm{mg} / \mathrm{kg})$ and perfused through the ascending aorta with $300 \mathrm{ml}$ of $4 \%$ paraformaldehyde in phosphate buffer (PB, $0.1 \mathrm{M}, \mathrm{pH}$ 7.4). Brains were dissected and coronal vibratome sections (50 $\mu \mathrm{m}$ thickness) were taken at the SN level, collected in $\mathrm{PB}$ and stored until use at $-20^{\circ} \mathrm{C}$ in $\mathrm{PB}$ containing $30 \%$ glycerol and $30 \%$ ethylene glycol.

\section{Immunofluorescent labeling and confocal microscopy}

Immunolabeling was performed on free-floating sections. Blocking step was first performed $1 \mathrm{~h}$ at room temperature in $10 \%$ normal goat or donkey serum (depending on the secondary antibodies used) diluted in $0.1 \mathrm{M}$ phosphate buffered $0.9 \%$ saline (PBS, pH 7.4). Sections were then incubated overnight at $4{ }^{\circ} \mathrm{C}$ with the adequate primary antibodies (see Table 1) diluted in PBS. After extensive washes in PBS, sections were incubated $1 \mathrm{~h}$ at room temperature with dye-conjugated secondary antibodies (Thermofisher Scientific,Waltham MA, USA) diluted 1/200 in PBS. Alexa 488-donkey 
anti-guinea pig and Alexa 647-donkey anti-mouse were used for GLT1 and tyrosine hydroxylase (TH) co-labeling. Alexa 633 goat anti-guinea pig, Alexa 568 goat anti-mouse IGg2a and Alexa 488 goat anti-mouse IgG1 were used for simultaneous detection of either vesicular glutamate transporter 1 (VGLUT1) or vesicular glutamate transporter 2 (VGLUT2), used as specific markers of the two main types of glutamatergic terminals, along with $\mathrm{TH}$ and bassoon (a protein of the presynaptic active zone cytomatrix). Alexa 568 goat anti-mouse IGg2a and Alexa 488 goat anti-mouse IgG1 were used for simultaneous detection of gephyrin, used as a specific marker of inhibitory synapses, and bassoon. Some sections were processed as described but without primary antibodies to evaluate non-specific staining. Images of fluorescent labeling were acquired on a confocal microscope (Zeiss LSM 510). High resolution optical sections were taken with a $64 \mathrm{X}$ oil immersion objective (NA: 1.4). Pinhole size was set to Airy one. Zoom was adjusted in order to obtain a pixel size of $0.07 \times 0.07 \mu \mathrm{m}^{2}$.

\section{Quantification of synapse densities}

Synapse counting was performed using the optical dissector on stacks of high resolution confocal images spaced by $0.33 \mu \mathrm{m}$ along the $\mathrm{z}$ axis. Excitatory synapses were identified by the apposition of bassoon labeling with the labeling of either VGLUT1 or VGLUT2. Bassoon labeling was found throughout the thickness of the section. On the contrary, VGLUT1 and VGLUT2 labelings exhibited limited penetration in the depth of the tissue. Their fluorescence was detected in the first 2 or 3 micrometers from the surface only with rapid attenuation along the $\mathrm{z}$ axis. To prevent a possible bias due to varying detection of VGLUTs along the $\mathrm{z}$ axis, a single pair of optical sections was retained in each stack. The reference section was taken at the peak of VGLUT1 or VGLUT2 fluorescence intensity and the look-up section immediately $(330 \mathrm{~nm})$ beneath. Only bassoon puncta found in the reference section in association with VGLUT2 or VGLUT1 but not visible in the lookup section were counted (see Fig. 6B,C).

\section{Immunoperoxidase staining and electron microscopy}

Free-floating vibratome sections were successively incubated $1 \mathrm{~h}$ at room temperature in $10 \%$ normal donkey serum in PBS and overnight at $4{ }^{\circ} \mathrm{C}$ with the anti-GLT1 antibody (1/1000 in PBS). After extensive washes in PBS, sections were incubated $1 \mathrm{~h}$ at room temperature with a donkey anti-guinea pig biotinylated secondary antibody (1/200 in PBS, Jackson ImmunoResearch Europe, Cambridge, UK) followed by avidin-biotin-peroxidase complex (ABC kit, Vector Laboratory, Burlingame, CA, USA, $1 \mathrm{~h}$ at room temperature). Peroxidase activity was revealed using 3,3diaminobenzidine tetrahydrochloride $(0,05 \%$ in $\mathrm{PB})$. Sections were then stained with $1 \%$ osmium tetroxide in PB (45 min) followed by $0.5 \%$ uranyl acetate in distilled water (45 min), dehydrated in increasing alcohol concentrations then propylene oxide and flat embedded in Durcupan ACM Fluka 
(Sigma-Aldrich). After polymerization of the resin, the SN was dissected and re-embedded in Durcupan blocks. Ultrathin sections $(80 \mathrm{~nm})$ were obtained on a Reichert Ultracut ultramicrotome and collected on formvar-coated single slot grids. Because of the limited penetration of the GLT1 antibody (no more than 3-4 $\mu \mathrm{m}$ from the surface of the tissue), ultrathin sections were taken from the most superficial portions of immunoperoxidase-stained tissue.

\section{Stereological analysis}

Stereological analysis was performed on digital electron microscope images obtained from 3 animals (see Table 2). The average density of astrocyte membranes in the neuropil (i.e. the membrane area of immunostained astrocyte processes per unit volume of tissue) was estimated for the $\mathrm{SNr}$ and the $\mathrm{SNc}$, separately, using the point-intersection counting method. A grid made of equally-spaced test lines was placed on each micrograph. Intersections between membranes of immunoreactive profiles and test lines were counted. The astrocyte membrane density $\mathrm{S}_{\mathrm{V}}$ (in $\mu \mathrm{m}^{2} / \mu \mathrm{m}^{3}$ ) was estimated according to the following formula:

$\mathrm{S}_{\mathrm{V}}=2 * \mathrm{I} / \mathrm{L}_{\mathrm{T}}$

where $\mathrm{I}$ is the total number of intersections and $\mathrm{L}_{\mathrm{T}}$ the total test lines length.

The relationships between immunostained astrocytic processes and synapses were analyzed by measuring 3 parameters on high resolution images of synaptic profiles obtained from tissue samples originating from 5 animals (Table 2). Asymmetrical and symmetrical synapses were separately analyzed. Asymmetrical synapses, defined as excitatory, were identified by the presence of a recognizable postsynaptic density whereas symmetrical synapses, defined as inhibitory, were identified by the presence of presynaptic dense projections without any recognizable postsynaptic density. The distance between the synapse (axone-dendrite interface) and the nearest glial process and the proportion of presynaptic coverage (proportion of axon bouton plasma membrane apposed to glial processes) were measured using Image J (RRID:SCR_003070). The average proportion of synaptic diameter covered by glia was estimated by edges counting on the same images of synaptic profiles. This method is based on the probability of having the plane of section passing through the apposed glia. It requires no serial sectioning, but nevertheless provides estimates that are very close to values obtained by three-dimensional reconstruction (Chounlamountry and Kessler 2011). Briefly, the numbers of edges of the axon-dendrite interface directly apposed to immunoreactive glia were counted on each synaptic profile and expressed as percent of the total number of edges, i.e. two-times the number of synaptic profiles (see Fig. 5B). Statistical comparison between distributions obtained for asymmetrical and symmetrical synapses was performed by $\chi^{2}$ analysis. 


\section{RESULTS}

\section{GLT1-immunoreactive structures in the SN}

In preliminary experiments, we found that substantial GLT1-immunofluorescent labeling was present both in SNc and SNr (Fig. 1A). In contrast, the immunolabeling of GLAST was very faint and close to background levels obtained on control sections incubated without any primary antibody (not shown). We therefore used GLT1 immunolabeling to identify astroglial cells and processes. At low magnification, GLT1 immunofluorescence appeared homogeneous throughout the rostrocaudal extent of the SN with roughly identical levels in SNc and SNr (Fig. 1A3). At higher magnification, GLT1 immunolabeling had a mesh-like aspect (Fig. 1B,C). Strongly fluorescent thin processes, presumably corresponding to astroglial extensions, were scattered in a non-immunoreactive matrix. Because of the high density of immunoreactive processes, it was not possible to clearly identify GLT1-positive perikarya in this material. In sections counter-labeled with anti-TH antibodies, dopaminergic cell bodies and neurites were frequently found in close apposition (i.e. $<1 \mu \mathrm{m})$ with GLT1-positive presumptive astroglial processes (Fig. 1C). Electron microscope examination of immunoperoxidase-stained tissue confirmed that GLT1-positive structures in the SN mainly corresponded to astroglial processes scattered in the neuropil (Fig. 2A,C). These immunoreactive structures were frequently very thin, consisting of apposed plasma membranes without much cytoplasm in between. GLT1-immunostaining was also found in the perikarya of astroglial cells (Fig. 2B). In labeled structures, peroxidase product deposits were present both at the internal face of the plasma membrane, delineating its entire extent, and within the cytoplasm. We used stereological techniques to quantify astroglial membranes densities in the SN. Measurements performed on 3 animals (see Table 2 for samples origin) showed that the densities of astroglial plasma membranes were $0.96+/-0.19 \mu \mathrm{m}^{2} / \mu \mathrm{m}^{3}$ in the neuropil of the SNc and $1.02+/-0.12 \mu \mathrm{m}^{2} / \mu^{3}$ in the neuropil of SNr. GLT1 positive astroglial processes were also found in close association with large dendrites and neuronal perikarya (Fig. 2D and E). Four perikaryal profiles were present in tissue samples used to quantify the density of glial membranes in the SNc. All 4 exhibited extensive coverage by glia with portions of their plasma membrane directly apposed to GLT1-positive processes ranging from $60 \%$ to $84 \%$, depending on the profile. GLT1 immunoreactivity was also detected in perivascular astrocyte end-feet ensheathing blood vessels (Fig. 3 A,B). GLT1 immunolabeling never occurred in neuronal elements, including axonal boutons.

\section{Ultrastructural relationships between GLT1 immunoreactivity and synapses in the SN}

One main role of GLT1-expressing glia is to remove from the extracellular space the glutamate released at excitatory synapses in order to prevent the occurrence of excitotoxic events. We therefore examined in greater details the relationships between excitatory synapses and GLT1- 
immunoreactive glial processes in the SN. We analyzed a sample of 134 asymmetrical synaptic profiles identified by the presence of a recognizable postsynaptic density (Fig. 4 A-E, arrows) and obtained from 4 different animals (see Table 2). We measured the proportion of glial coverage on the presynaptic side (Fig. 5A) and on the perimeter of the axon-dendrite apposition (Fig. 5B) as described in the method section. The extent of glial apposition was extremely variable depending on the synaptic profile. On average, coverage by GLT1-immunoreactive glia amounted to $43 \%$ of the axon bouton plasma membrane surface and $32 \%$ of the perimeter of the axon-dendrite interface. We next wondered whether the $30-40 \%$ coverage level found at excitatory synapses might have resulted from random appositions between glial processes and synapses. We measured the density of neuronal membranes in the SN neuropil using the point-intersection counting method. We obtained an average density of $6.8 \mu \mathrm{m}^{2} / \mu \mathrm{m}^{3}$, meaning that glial membranes $\left(\approx 1 \mu \mathrm{m}^{2} / \mu \mathrm{m}^{3}\right)$ amounted to about $13 \%$ of the plasma membranes found in the SN neuropil. Thus, assuming random appositions between glial and neuronal processes, coverage levels at asymmetrical synapses should be close to $13 \%$. The $30-40 \%$ coverage levels of asymmetrical synapses found here indicates higher occurrence of GLT1-expressing glial processes close to or around excitatory synapses. We next asked whether there was also an increased presence of glia at inhibitory synapses. We analyzed 97 symmetrical synaptic profiles (see Table 2) identified by the presence of presynaptic dense projections without any recognizable postsynaptic density (Fig. 4E, arrowheads). We found that glial coverage was present over $22 \%$ of the axon bouton plasma membrane surface and $18 \%$ of the perimeter of the axon-dendrite interface on average. These values were slightly higher than those expected from random appositions but substantially lower than those found at excitatory synapses. We also provided evidence that the average distance between the axon-dendrite interface and the nearest glial process was longer for inhibitory vs excitatory synapses (Fig. 5C). Comparisons of glial coverage and distance to glia distributions across synaptic profiles confirmed that differences between symmetrical and asymmetrical were significant (Fig. 5), suggesting that inhibitory synapses were less attractive for glia than excitatory synapses.

\section{Densities of glutamatergic synapses in the $S N$}

Electron microscope observations of SN tissue performed to quantify GLT1-expressing glial membrane densities also showed that excitatory synapses were scarce in the SN and considerably less frequent than inhibitory synapses. From a total of 374 synaptic profiles identified in these tissue samples, we found that 43 only (i.e. 11.5\%) were asymmetrical. Taking into account the total surface of the tissue sampled $\left(4493 \mu^{2}\right)$ and the section thickness $(80 \mathrm{~nm})$ and assuming an average diameter of $200 \mathrm{~nm}$ for the PSD/active zone apposition, this low number of occurrences of asymmetrical synaptic profiles was indicative of low densities of excitatory synapses, presumably 
in the range of 0.01-0.05 per $\mu \mathrm{m}^{3}$. We next used confocal imaging with unbiased counting methods in order to obtain more precise and trustable estimates of excitatory synapses densities in the SN. In line with electron microscope data, we found that few bassoon puncta were associated with the glutamatergic terminal markers VGLUT1 or VGLUT2 while most of them were associated with gephyrin, confirming that excitatory synapses were greatly outnumbered by inhibitory synapses in the SN (Fig. 6). Counting of VGLUT1- and VGLUT2-positive synapses was separately performed in the SNc and the SNr on tissue samples from 4 animals (see Table 2) using the optical dissector and a $330 \mathrm{~nm}$ spacing between the reference and the look-up sections (see Fig. 6B,C). Data obtained confirmed that the SN had very low densities of excitatory synapses, especially in the $\mathrm{SNr}$ ( 0.01 per $\mu \mathrm{m}^{3}$ versus 0.025 per $\mu \mathrm{m}^{3}$ for $\mathrm{SNc}$ ) and that VGLUT1-positive synapses were 2 to 3 times less numerous than VGLUT2-positive synapses (Table 3).

\section{DISCUSSION}

It is generally assumed that astrocytes are fewer in the SN than in most other parts of the brain. This assumption is mainly based on data obtained using GFAP as a marker of glial cells both in Human and rodents (Damier et al. 1993; Ji et al. 2008). Using GFAP immunolabeling to identify astrocytes may have resulted in a considerable underestimation of glial presence in the SN. First, GFAP antibodies either fail to label or only weakly stain most protoplasmic astrocytes found in grey matter (see for instance Miller and Raff 1984). Second, even for those protoplasmic astrocytes that express the marker, the major part of the cell arborization remains undetectable since the labeling is restricted to the perikaryon and the largest cell processes, sparing the numerous cisternae and filopodia that made up most of the astrocyte volume and cell surface (Chao et al. 2002). Here using GLT1which is highly expressed throughout the cell arborization, we found that the entire rat SN was filled with a dense meshwork of immunoreactive astrocytic processes. Stereological analysis showed that the density of astrocyte membranes was substantial (close to $1 \mu \mathrm{m}^{2} / \mu \mathrm{m}^{3}$ ) both in the $\mathrm{SNc}$ and in the SNr, well below that found in the cerebellum $\left(3.8 \mu \mathrm{m}^{2} / \mu^{3}\right.$; Lehre and Danbolt 1998) but only slightly lower than those measured in the cortex $\left(1.4 \mu \mathrm{m}^{2} / \mu \mathrm{m}^{3}\right.$; Jones and Greenough 1996) and the hippocampus (1.4 $\mathrm{mm}^{2} / \mu \mathrm{m}^{3}$; Lehre and Danbolt 1998). We also showed that small blood vessels in the SN were extensively ensheathed by perivascular end-feet, a finding that contradicted previous conclusions based on astroglial processes detection by GFAP (Ji et al. 2008). In addition, we found that both the SNc and the SNr had very low densities of excitatory synapses as compared to other brain regions. As a consequence, the ratio of astroglial membrane surface density to synapse density was very high, $38 \mu \mathrm{m}^{2}$ in the $\mathrm{SNc}$ and up to $100 \mu \mathrm{m}^{2}$ in the $\mathrm{SNr}$ (compared to roughly $1 \mu^{2}$ in the hippocampus). Thus, it may be concluded that, in basal 
conditions at least, there was no obvious glial deficit in the rat SN as compared to other brain regions. Furthermore, using immunofluorescence, we observed numerous appositions between GLT1- and TH-immunoreactive profiles suggesting that astroglial cells may efficiently control the microenvironment of nigral dopaminergic neurons. This view is further substantiated by electron microscope data which demonstrate extensive glial ensheatment of neuronal cell bodies and large dendrites in the SNc.

GLT1 was originally thought to be a specific glial glutamate transporter. It was latter demonstrated to be present in many axon terminals as well as in some spines and dendrites in the cortex and the hippocampus (Chen et al. 2004; Furness et al. 2008; Melone et al. 2009; Petr et al. 2015). Here, GLT1 immunolabeling was restricted to glial elements. It could be that the sensitivity of the labeling method we used was insufficient to detect the lower GLT1 protein levels present in axons (Melone et al. 2009). It also could be that glutamatergic fibers innervating the SN have no or very few presynaptic glutamate transporters, contrary to those found in telencephalic regions.

We found that excitatory nigral synapses had on average one third (32\%) of their perimeters bounded by glial processes. This is far less than averages reported for excitatory synapses in the cerebellar molecular layer (65\% and $87 \%$ for parallel and climbing fiber synapses, respectively; Xu Friedman et al. 2001) but slightly more than the average for excitatory synapses in the stratum radiatum of the hippocampal field CA1 (25\%; Ventura and Harris 1999). It should be kept in mind that huge differences in glial wrapping exist not only between synapses from different brain regions, or synapses from different subpopulations in the same brain region, but also between synapses belonging to the same apparently homogenous population. The reasons for this variability are currently unknown but a large body of evidence indicates that the extent of perisynaptic glia depends on the level of activity of the synapse. Astrocytes processes are highly mobile structures. Numerous studies have shown that enhancing neuronal activity in a given brain region increases their motility as well as glial coverage of excitatory synapses (Jones and Greenough 1996; Genoud et al. 2006; Lushnikova et al. 2009; Villalba and Smith 2011; Bernardinelli et al. 2014; PerezAlvarez et al.; Chounlamountry et al. 2015). Thus, it has been suggested that glutamate or some other compound released by active excitatory synapses attracts astrocyte processes and stimulates their growth. In line with this hypothesis, our data showed that glial occurrence was higher at excitatory than inhibitory synapses suggesting that synapses that released glutamate were more attractive for glia.

Whatever the case, the fact that nigral excitatory synapses had on average two thirds of their perimeters free from glia suggests that significant glutamate spill-out may occur and result in extrasynaptic NMDA receptor activation. Accordingly, electrophysiological studies indicate that 
NMDA receptor currents induced in nigral neurons by high frequency afferent stimulation originate at least in part from receptors distant from the activated synapses (Wild et al. 2015). If most of the transmitter released at nigral synapses escapes the cleft, one may wonder whether sustained activity could result in prolonged increases in ambient glutamate levels and could thereby induce excitotoxic activation of NMDA receptors. Long-lasting increases in ambient glutamate levels could conceivably occur if the rate of release locally exceeds the clearance capacity by glial transporters. The readily releasable pool at a central synapse includes at most two dozens of vesicles with a mean refilling time of about 12 second (Stevens and Tsujimoto 1995). Thus, in case of sustained activity each synapse should release at most 2 vesicles per second, each vesicle containing an average of 3000 glutamate molecules (Savtchenko et al. 2013). Taking into account synapse densities, maximal release rates should be 600 and 1500 glutamate molecules per second and per $\mu \mathrm{m}^{3}$ of neuropil in the $\mathrm{SNr}$ and the SNc, respectively. The reported tissue concentration of the GLT1 transporter in the hippocampus is 12000 molecules per $\mu \mathrm{m}^{3}$, resulting in an average surface density of 8500 transporter molecules per $\mu \mathrm{m}^{2}$ of glial membrane (Lehre and Danbolt 1998). Since, the GLT1 tissue content of the mesencephalon is about one third of that found in the hippocampus (Lehre et al. 1995), it can be assumed that there should be about 4000 GLT1 molecules per $\mu \mathrm{m}^{3}$ in the SN (meaning that the average surface density should be 4000 transporter molecules per $\mu^{2}$ of glial membrane). Since the cycling time of the GLT1 transporter is 10-20 ms at physiological temperature (Bergles et al. 2002), the theoretical uptake rate should be at least 20000 glutamate molecules per second and per $\mu \mathrm{m}^{3}$ of neuropil. This value is at least one order of magnitude greater than the calculated maximal release rates, suggesting that glutamate uptake capacities in the rat SN largely exceed release capacities and would not be overwhelmed in physiological conditions even in case of high, sustained activity of afferent glutamatergic systems.

To conclude, our study shows that the rat SN is filled with a dense meshwork of astrocyte processes, a finding in discrepancy with the assumption that a local deficit in astroglia may contribute to the high vulnerability of nigral dopaminergic neurons. Our study also indicates that the disposition of glia at nigral excitatory synapses may favor glutamate spill-over. However, large increases in extracellular glutamate levels are unlikely to occur in view of the very low number of excitatory synapses found in the substantia nigra neuropil. 


\section{REFERENCES}

Ambrosi G, Cerri S, Blandini F (2014) A further update on the role of excitotoxicity in the pathogenesis of Parkinson's disease. J Neural Transm (Vienna). 121:849-859. doi: 10.1007/s00702013-1149-z.

Assous M, Had-Aissouni L, Gubellini P, Melon C, Nafia I, Salin P, Kerkerian-Le-Goff L, Kachidian P (2014) Progressive Parkinsonism by acute dysfunction of excitatory amino acid transporters in the rat substantia nigra. Neurobiol Dis. 65:69-81. doi: 10.1016/j.nbd.2014.01.011.

Bergles DE, Tzingounis AV, Jahr CE (2002) Comparison of coupled and uncoupled currents during glutamate uptake by GLT-1 transporters. J Neurosci. 22:10153-10162.

Bernardinelli Y, Nikonenko I, Muller D (2014) Structural plasticity: mechanisms and contribution to developmental psychiatric disorders. Front Neuroanat. 3:123. doi: 10.3389/fnana.2014.00123.

Chao TI, Rickmann M,Wolff JR. 2002. The synapse-astrocyte boundary: an anatomical basis for an integrative role of glia in synaptic transmission. In: Volterra A, Magistretti P, Haydon PG, editors. The tripartite synapse: Glia in synaptic transmission. Oxford: UP. p 3-23.

Chen W, Mahadomrongkul V, Berger UV, Bassan M, DeSilva T, Tanaka K, Irwin N,Aoki C, Rosenberg PA (2004) The glutamate transporter GLT1a is expressed in excitatory axon terminals of mature hippocampal neurons. J Neurosci. 24:1136-1148.

Chounlamountry K, Boyer B, Penalba V, François-Bellan AM, Bosler O, Kessler JP, Strube C (2015) Remodeling of glial coverage of glutamatergic synapses in the rat nucleus tractus solitarii after ozone inhalation. J Neurochem. 134:857-864. doi: 10.1111/jnc.13193.

Chounlamountry K, Kessler JP. (2011) The ultrastructure of perisynaptic glia in the nucleus tractus solitarii of the adult rat: Comparison between single synapses and multisynaptic arrangements. Glia. 59: 655-663. doi: 10.1002/glia.21135.

Damier P, Hirsch EC, Zhang P, Agid Y, Javoy-Agid F (1993) Glutathione peroxidase, glial cells and Parkinson's disease. Neuroscience. 52:1-6.

Danbolt NC. (2001) Glutamate uptake. Prog Neurobiol. 65:1-105.

Dringen R, Pfeiffer B, Hamprecht B (1999) Synthesis of the antioxidant glutathione in neurons: supply by astrocytes of CysGly as precursor for neuronal glutathione. J Neurosci. 19:562-569.

Furness DN, Dehnes Y, Akhtar AQ, Rossi DJ, Hamann M, Grutle NJ, Gundersen V, Holmseth S, Lehre KP, Ullensvang K, Wojewodzic M, Zhou Y, Attwell D, Danbolt NC (2008) A quantitative assessment of glutamate uptake into hippocampal synaptic terminals and astrocytes: new insights 
into a neuronal role for excitatory amino acid transporter 2 (EAAT2). Neuroscience. 157:80-94. doi:10.1016/j.neuroscience.2008.08.043.

Genoud C, Quairiaux C, Steiner P, Hirling H, Welker E, Knott GW. (2006) Plasticity of astrocytic coverage and glutamate transporter expression in adult mouse cortex. PLoS Biol. 4:e343. doi: 10.1371/journal.pbio.0040343

Hirsch EC (2000) Glial cells and Parkinson's disease. J Neurol. 247 Suppl2:II58-62.

Ji KA, Eu MY, Kang SH, Gwag BJ, Jou I, Joe EH (2008) Differential neutrophil infiltration contributes to regional differences in brain inflammation in the substantia nigra pars compacta and cortex. Glia. 56:1039-1047. doi: 10.1002/glia.20677.

Joe EH, Choi DJ, An J, Eun JH, Jou I, Park S (2018) Astrocytes, Microglia, and Parkinson's Disease. Exp Neurobiol. 27:77-87. doi: 10.5607/en.2018.27.2.77.

Jones TA, Greenough WT (1996) Ultrastructural evidence for increased contact between astrocytes and synapses in rats reared in a complex environment. Neurobiol Learn Mem. 65:48-56.

Kostuk EW, Cai J, Iacovitti L (2019) Subregional differences in astrocytes underlie selective neurodegeneration or protection in Parkinson's disease models in culture. Glia. 67:1542-1557. doi: 10.1002/glia.23627.

Lehre KP, Danbolt NC. 1998. The number of glutamate transporter subtype molecules at glutamatergic synapses: chemical and stereological quantification in young adult rat brain. J Neurosci. 18:8751-8757.

Lushnikova I, Skibo G, Muller D, Nikonenko I. (2009) Synaptic potentiation induces increased glial coverage of excitatory synapses in CA1 hippocampus. Hippocampus. 19:753-762. doi: 10.1002/hipo.20551.

Melone M, Bellesi M, Conti F (2009) Synaptic localization of GLT-1a in the ratsomatic sensory cortex. Glia. 57:108-117. doi: 10.1002/glia.20744.

Meredith GE, Totterdell S, Beales M, Meshul CK (2009) Impaired glutamate homeostasis and programmed cell death in a chronic MPTP mouse model of Parkinson's disease. Exp Neurol. 219:334-340. doi: 10.1016/j.expneurol.2009.06.005.

Miller RH, Raff MC (1984) Fibrous and protoplasmic astrocytes are biochemically and developmentally distinct. J Neurosci. 4:585-592.

Perez-Alvarez A, Navarrete M, Covelo A, Martin ED, Araque A (2014) Structural and functional plasticity of astrocyte processes and dendritic spine interactions. J Neurosci. 34:12738-12744. doi: 


\subsection{3/JNEUROSCI.2401-14.2014.}

Petr GT, Sun Y, Frederick NM, Zhou Y, Dhamne SC, Hameed MQ, Miranda C, Bedoya EA, Fischer KD, Armsen W, Wang J, Danbolt NC, Rotenberg A, Aoki CJ, Rosenberg PA (2015) Conditional deletion of the glutamate transporter GLT-1 reveals that astrocyticGLT-1 protects against fatal epilepsy while neuronal GLT-1 contributessignificantly to glutamate uptake into synaptosomes. J Neurosci. 35:5187-5201. doi: 10.1523/JNEUROSCI.4255-14.2015.

Rappold PM, Tieu K (2010) Astrocytes and therapeutics for Parkinson's disease. Neurotherapeutics. 7:413-423. doi: 10.1016/j.nurt.2010.07.001.

Sagara JI, Miura K, Bannai S (1993) Maintenance of neuronal glutathione by glial cells. J Neurochem. 61:1672-1676.

Savtchenko LP, Sylantyev S, Rusakov DA (2013) Central synapses release a resource-efficient amount of glutamate. Nat Neurosci. 16:10-12. doi: 10.1038/nn.3285.

Stevens CF, Tsujimoto T (1995) Estimates for the pool size of releasable quanta at a single central synapse and for the time required to refill the pool. Proc Natl Acad Sci U S A. 92:846-849.

Sulzer D, Surmeier DJ (2013) Neuronal vulnerability, pathogenesis, and Parkinson's disease. Mov Disord. 28:715-724. doi: 10.1002/mds.25187.

Takuma K, Baba A, Matsuda T (2004) Astrocyte apoptosis: implications for neuroprotection. Prog Neurobiol. 72:111-127. doi:10.1016/j.pneurobio.2004.02.001.

Teismann P, Schulz JB (2004) Cellular pathology of Parkinson's disease: astrocytes, microglia and inflammation. Cell Tissue Res. 318:149-161. doi: 10.1007/s00441-004-0944-0.

Ventura R, Harris KM (1999) Three-dimensional relationships between hippocampal synapses and astrocytes. J Neurosci. 19:6897-6906.

Villalba RM, Smith Y (2011) Neuroglial plasticity at striatal glutamatergic synapses in Parkinson's disease. Front Syst Neurosci. 5:68. doi: 10.3389/fnsys.2011.0006.

Wild AR, Bollands M, Morris PG, Jones S (2015) Mechanisms regulating spill-over of synaptic glutamate to extrasynaptic NMDA receptors in mouse substantia nigra dopaminergic neurons. Eur J Neurosci. 42:2633-2643. doi: 10.1111/ejn.1307 .

Xu-Friedman MA, Harris KM, Regehr WG (2001) Three-dimensional comparison of ultrastructural characteristics at depressing and facilitating synapses onto cerebellar Purkinje cells. J Neurosci. 21:6666-6672. 


\begin{tabular}{|c|c|c|c|c|c|c|}
\hline Name/RRID & $\begin{array}{l}\text { Host/Isotype } \\
\text { /clone }\end{array}$ & Antigen & Source & Cat. number & Batch & $\begin{array}{l}\text { Dilutio } \\
\mathrm{n}\end{array}$ \\
\hline $\begin{array}{l}\text { Anti-GLT1 } \\
\text { /AB_90949 }\end{array}$ & Guinea pig & $\begin{array}{l}\text { Carboxy-terminus of rat } \\
\text { GLT1 }\end{array}$ & $\begin{array}{l}\text { Merck-KGaA, } \\
\text { Darmstadt, Germany }\end{array}$ & AB1783 & 1960854 & $1 / 1000$ \\
\hline $\begin{array}{l}\text { Anti-GLAST } \\
\text { /AB_90959 }\end{array}$ & Guinea pig & $\begin{array}{l}\text { Carboxy-terminus of rat } \\
\text { GLAST }\end{array}$ & $\begin{array}{l}\text { Merck-KGaA, } \\
\text { Darmstadt, Germany }\end{array}$ & AB1782 & LV1480429 & $1 / 1000$ \\
\hline $\begin{array}{l}\text { Anti-TH } \\
\text { /AB_2313764 }\end{array}$ & $\begin{array}{l}\text { Mouse/IgG1 } \\
\text { /LNC1 }\end{array}$ & $\begin{array}{l}\text { Recombinant tyrosine } \\
\text { hydroxylase }\end{array}$ & $\begin{array}{l}\text { Merck-KGaA, } \\
\text { Darmstadt, Germany }\end{array}$ & MAB318 & 2677893 & $1 / 1000$ \\
\hline $\begin{array}{l}\text { Anti-VGLUT1 } \\
\text { /AB_2301751 }\end{array}$ & Guinea pig & $\begin{array}{l}\text { Synthetic peptide from rat } \\
\text { VGLUT1 }\end{array}$ & $\begin{array}{l}\text { Merck-KGaA, } \\
\text { Darmstadt, Germany }\end{array}$ & AB5905 & 24041061 & $1 / 1000$ \\
\hline $\begin{array}{l}\text { Anti-VGLUT2 } \\
\text { /AB_1587626 }\end{array}$ & Guinea pig & $\begin{array}{l}\text { Synthetic peptide from rat } \\
\text { VGLUT2 }\end{array}$ & $\begin{array}{l}\text { Merck-KGaA, } \\
\text { Darmstadt, Germany }\end{array}$ & AB2251 & 2276424 & $1 / 1000$ \\
\hline $\begin{array}{l}\text { Anti-Bassoon } \\
\text { /AB_10618753 }\end{array}$ & $\begin{array}{l}\text { Mouse/IGg2a } \\
\text { /SAP7F407 }\end{array}$ & Recombinant rat bassoon & $\begin{array}{l}\text { Enzo LifeScience } \\
\text { New-York USA }\end{array}$ & VAM-PS003 & 11021131 & $1 / 500$ \\
\hline $\begin{array}{l}\text { Anti-Gephyrin } \\
\text { /AB_887717 }\end{array}$ & $\begin{array}{l}\text { Mouse/IGg1 } \\
\text { /mAb7a }\end{array}$ & $\begin{array}{l}\text { Native rat protein } \\
\text { (epitope : aa } 264 \text { to 276) }\end{array}$ & $\begin{array}{l}\text { Synaptic Systems } \\
\text { Gœttingen, Germany }\end{array}$ & 147011 & $147011 / 20$ & $1 / 1000$ \\
\hline
\end{tabular}

Table 1: Primary antibodies references and characteristics 


\begin{tabular}{|c|c|c|c|c|c|c|c|c|}
\hline \multirow[t]{3}{*}{ Rat \# } & \multicolumn{2}{|c|}{$\begin{array}{l}\text { Glial membrane densities. } \\
\text { Sampled surface (EM) }\end{array}$} & \multicolumn{2}{|c|}{$\begin{array}{c}\text { Glial coverage of } \\
\text { synapses. } \\
\text { Number of profiles (EM) }\end{array}$} & \multicolumn{4}{|c|}{$\begin{array}{c}\text { Synapse densities. } \\
\text { Sampled surface (confocal) }\end{array}$} \\
\hline & SNc & $\mathrm{SNr}$ & Excitatory & Inhibitory & \multicolumn{2}{|c|}{ SNc } & \multicolumn{2}{|c|}{$\mathrm{SNr}$} \\
\hline & & & & & VGLUT1 & VGLUT2 & VGLUT1 & VGLUT2 \\
\hline 1 & $1044 \mu \mathrm{m}^{2}$ & $972 \mu \mathrm{m}^{2}$ & 36 & 22 & $4242 \mu \mathrm{m}^{2}$ & $4242 \mu \mathrm{m}^{2}$ & $4242 \mu \mathrm{m}^{2}$ & $4242 \mu \mathrm{m}^{2}$ \\
\hline 2 & $520 \mu \mathrm{m}^{2}$ & $404 \mu \mathrm{m}^{2}$ & 16 & & $4242 \mu \mathrm{m}^{2}$ & $4242 \mu \mathrm{m}^{2}$ & $4242 \mu \mathrm{m}^{2}$ & $4242 \mu \mathrm{m}^{2}$ \\
\hline 3 & $396 \mu \mathrm{m}^{2}$ & $684 \mu \mathrm{m}^{2}$ & & 17 & $4242 \mu \mathrm{m}^{2}$ & & $4242 \mu \mathrm{m}^{2}$ & \\
\hline 4 & & & 36 & 27 & $2828 \mu \mathrm{m}^{2}$ & $4242 \mu \mathrm{m}^{2}$ & $1414 \mu \mathrm{m}^{2}$ & $4242 \mu \mathrm{m}^{2}$ \\
\hline 5 & & & 46 & 31 & $2828 \mu \mathrm{m}^{2}$ & $4242 \mu \mathrm{m}^{2}$ & $1414 \mu \mathrm{m}^{2}$ & $4242 \mu \mathrm{m}^{2}$ \\
\hline
\end{tabular}

Table 2. Origin of samples used for quantitative analysis. 


\begin{tabular}{c|c|c} 
& SNc & SNr \\
\hline VGLUT1-positive synapses & $0.006 \pm 0.005 . \mu \mathrm{m}^{-3}$ & $0.003 \pm 0.001 . \mu \mathrm{m}^{-3}$ \\
VGLUT2-positive synapses & $0.019 \pm 0.008 . \mu \mathrm{m}^{-3}$ & $0.007 \pm 0.004 . \mu \mathrm{m}^{-3}$
\end{tabular}

Table 3. Densities of VGLUT1- and VGLUT2-positive excitatory synapses (means \pm s.d.) in the SNc and the $\mathrm{SNr}$ of the rat. 
Fig. 1. GLT1 immunolabeling in the substantia nigra. A. Distribution of GLT1 immunofluorescence (green) in the ventrall midbrain (confocal mosaic image). Dopaminergic cells are counter-labeled by TH immunofluorescence (magenta). CP: Cerebellar Peduncle, ML: Median Lemniscus, SN: Substantia Nigra. The two adjacent boxed areas in A2 and A3 indicate regions used for electron microscope tissue sampling. SNc: Substantia Nigra pars compacta, SNr: Substantia Nigra pars reticulata. B and C. High resolution confocal images of GLT1 immunofluorescence in the pars compacta. Note the mesh-like aspect of the labeling and the close association of GLT1 immunoreactive processes with dopaminergic cell bodies and dendritic profiles. Scale bars: $200 \mu \mathrm{m}$ in $\mathrm{A}, 20 \mu \mathrm{m}$ in $\mathrm{B}$ and $10 \mu \mathrm{m}$ in $\mathrm{C}$.

Fig. 2. Fine structure of GLT1 immunolabeling in the substantia nigra. A. Neuropil of the pars compacta. Dark deposits of peroxidase reaction product indicative of GLT1 immunolabeling are present in thin elongated profiles scattered in the neuropil and presumably corresponding to astroglial processes (some indicated by arrows). B. A GLT1 immunoreactive astrocyte cell body in the pars compacta. Peroxidase reaction product is present in the cytoplasm and along the plasma membrane (arrows). C. Immunoreactive glial processes in the neuropil of the pars reticulata. Note the presence of a glomerulus made by a central dendritic profile (d) establishing symmetrical synapses (some indicated by arrowheads) with numerous axonal boutons. D and E. GLT1 immunoreactive processes in close apposition to a large proximal dendrite (D) and a neuronal cell body $(\mathrm{E})$ in the pars compacta. Scale bars: $1 \mu \mathrm{m}$ in $\mathrm{A}, \mathrm{C}$ and $\mathrm{D}$ and $2 \mu \mathrm{m}$ in B and F.

Fig. 3. GLTI immunolabeling in perivascular end-feet. A. Example of a capillary profile from the pars compacta completely ensheathed by a GLT-immunoreactive astrocyte end-foot (tiled image). Inset. Note the almost complete absence of cytoplasm in this part of the astrocyte end-foot. ec: endothelial cell; bm, basal membrane; As, astrocyte end-foot. B. Another example of a small vessel profile with ensheathing astrocyte end-foot. Scale bars: $1 \mu \mathrm{m}$ in A and $500 \mathrm{~nm}$ in B.

Fig. 4. Morphology of GLT1-expressing synaptic glia in the substantia nigra. Examples of excitatory synapses (indicated by arrows) established on dendritic spine (A-C) or shaft profiles (D,E) and of inhibitory synapses (indicated by arrowheads in E). The proportion of axonal and/or dendritic membrane covered by glia is strongly variable depending on the profile. In rare instances, 
extensive coverage by multi-lamelar glial sheet was found around synapses (as in A). The asterisk in E indicates a lightly immunoreactive glial profile. Scale bars: $500 \mathrm{~nm}$ in all panels.

Fig. 5. Comparison of glial coverage at excitatory and inhibitory synapses. A. Glial coverage of the axonal bouton. Left panel: the length of plasma membrane apposed to glia (arrowheads) was measured on each bouton profile (solid line) and expressed as percent of the total length of the bouton membrane (solid line+dashed line), excluding the axon dendrite synaptic interface. Right panel: distribution histograms obtained for the 134 excitatory synaptic profiles and the 97 inhibitory synaptic profiles analyzed. Chi-squared analysis indicates that the two distributions are significantly different, excitatory synapses exhibiting more extensive coverage as compared to inhibitory synapses (43\% versus $22 \%$ respectively, on average). B. Glial coverage of the axon dendrite interface. Left panel: the number of edges $(0,1$ or 2$)$ of the axon-dendrite interface in contact with glia (arrowheads) was counted for each synaptic profile. Right panel: distribution histograms obtained for for the 134 excitatory synaptic profiles and the 97 inhibitory synaptic profiles analyzed. Chi-squared analysis indicates that the two distributions are significantly different, excitatory synaptic profiles having an higher proportion of edges in contact with glia as compared to inhibitory synaptic contact. Average values, obtained by summing the numbers of edges in contact with glia at each profile and by dividing the result by the total number of edges (two times the number of synaptic profiles) were $32 \%$ and $18 \%$ for excitatory and inhibitory synapses, respectively. C. Distance between astrocytes and synapses. Right pannel: the length of the shortest extracellular path between the ADI and neighboring glial processes (either covering the synapse or not) was measured for each synaptic profile. Right pannel: distribution histograms obtained for the 134 excitatory synaptic profiles and the 97 inhibitory synaptic profiles analyzed. Chi-squared analysis indicates that the two distributions are significantly different, excitatory synapses being closer to glia as compared to inhibitory synapses.

Fig. 6. Excitatory synapse densities in the substantia nigra. A. VGLUT2-bassoon co-labeling in the pars compacta. TH immunofluorescence was used as landmark. Note that few bassoon puncta were associated with VGLUT2 labeling and thus assumed to correspond to glutamatergic synapses. B and C. Zoomed images of the boxed area in A taken on reference (B) and look up (C) optical sections spaced by $330 \mathrm{~nm}$. Dissector counting was performed on the basis of the bassoon labeling only. In spite of VGLUT2 labeling being present on both optical sections, the bassoon puncta indicated by an arrowhead was counted because it was present on the reference section but no 
longer visible on the look-up section. On the contrary, the bassoon puncta indicated by an arrow was not counted because it was visible on both section. D. VGLUT1-bassoon co-labeling in the pars compacta. Note the very low density of VGLUT1-immunoreactive terminals. E.VGLUT2-bassoon co-labeling in the pars reticulata. Note the presence of synaptic glomeruli reminiscent of those observed on electron microscope images (e.g. Fig. 2D and Fig. 4E). F. Gephyrin-bassoon colabeling indicate that synaptic glomeruli found in the pars reticulata are mainly made of inhibitory synapses. Scale bars: $5 \mu \mathrm{m}$ except in B,C and F $(2 \mu \mathrm{m})$. 

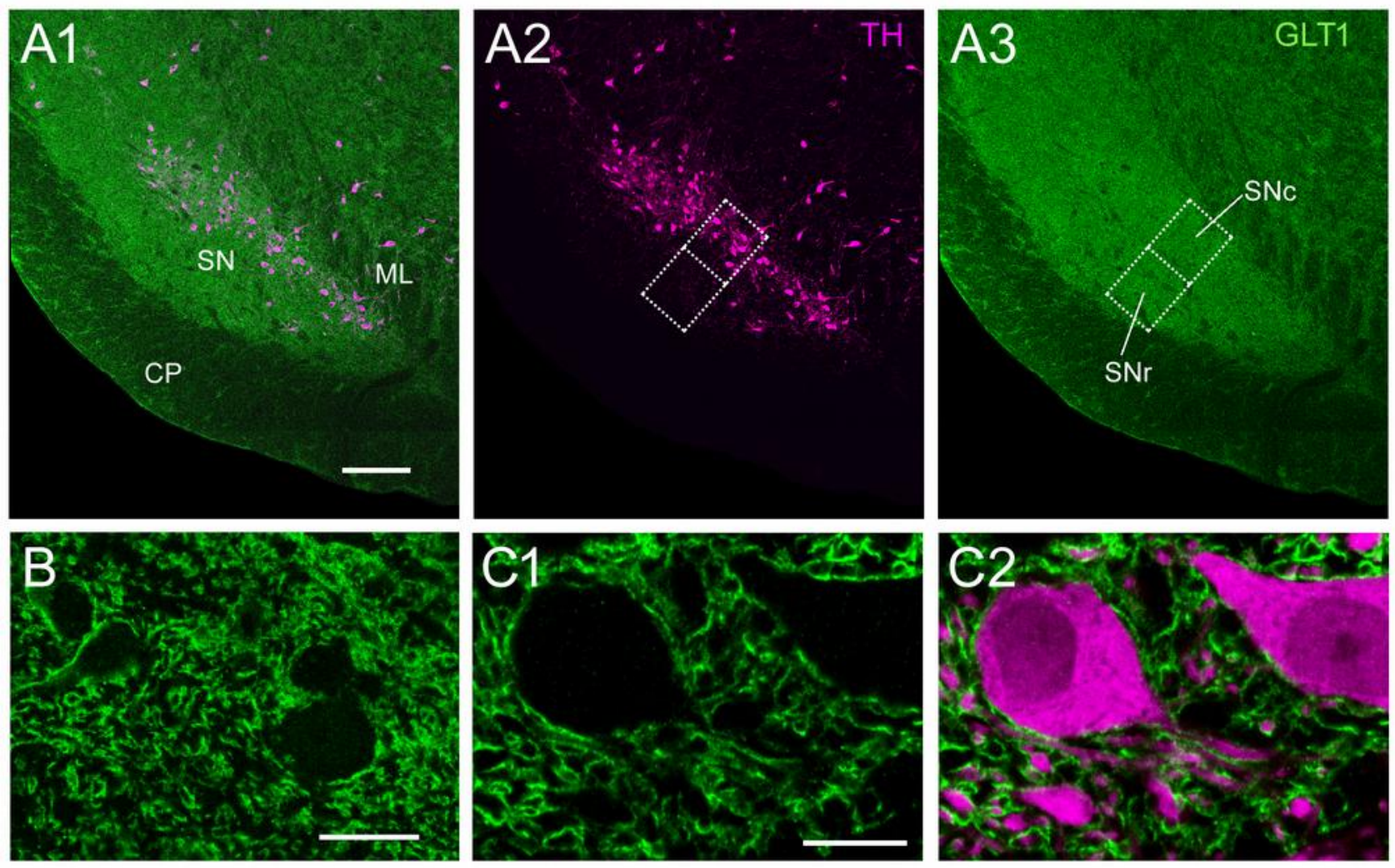

Figure 1 

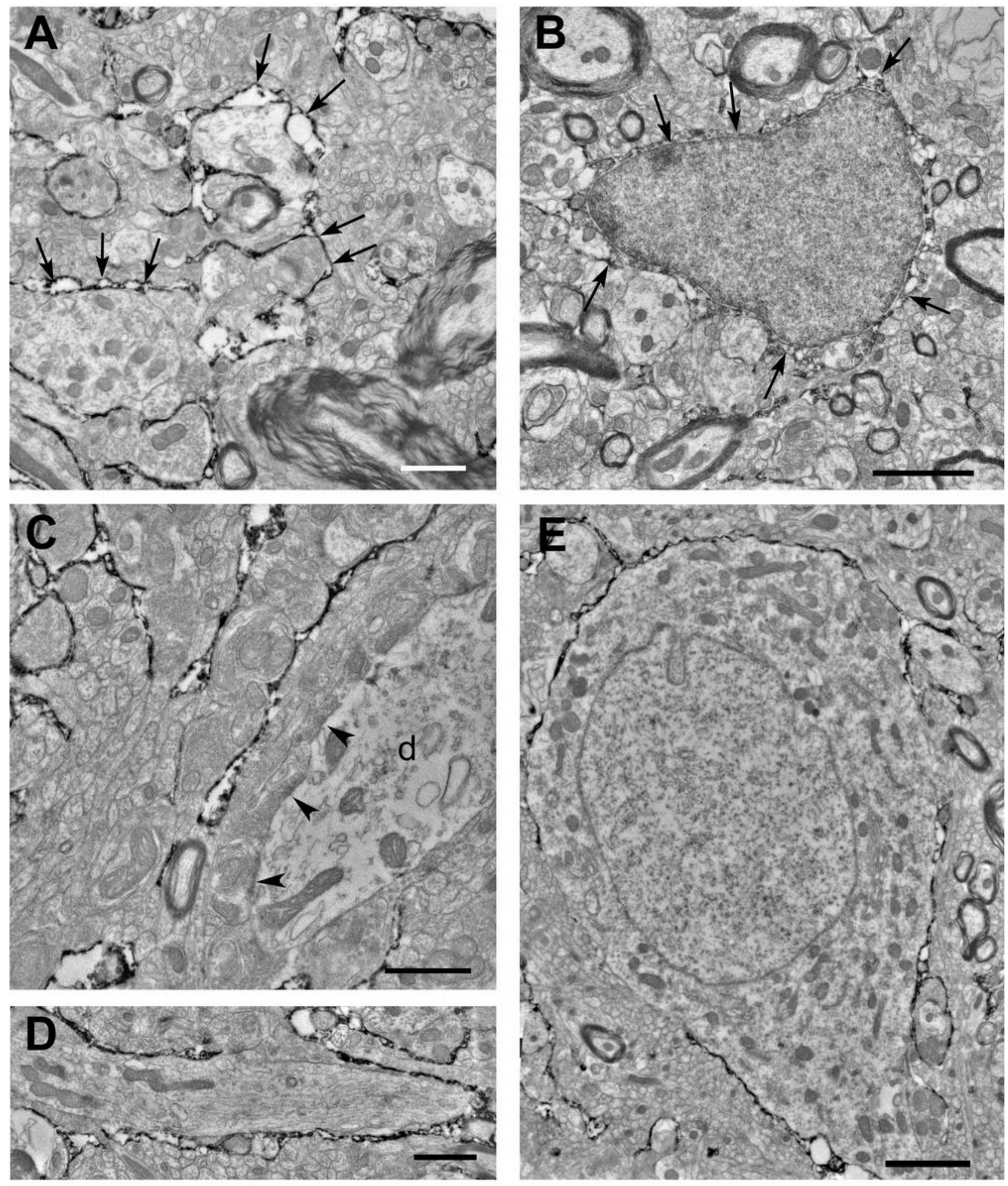

Figure 2 
Figure 3
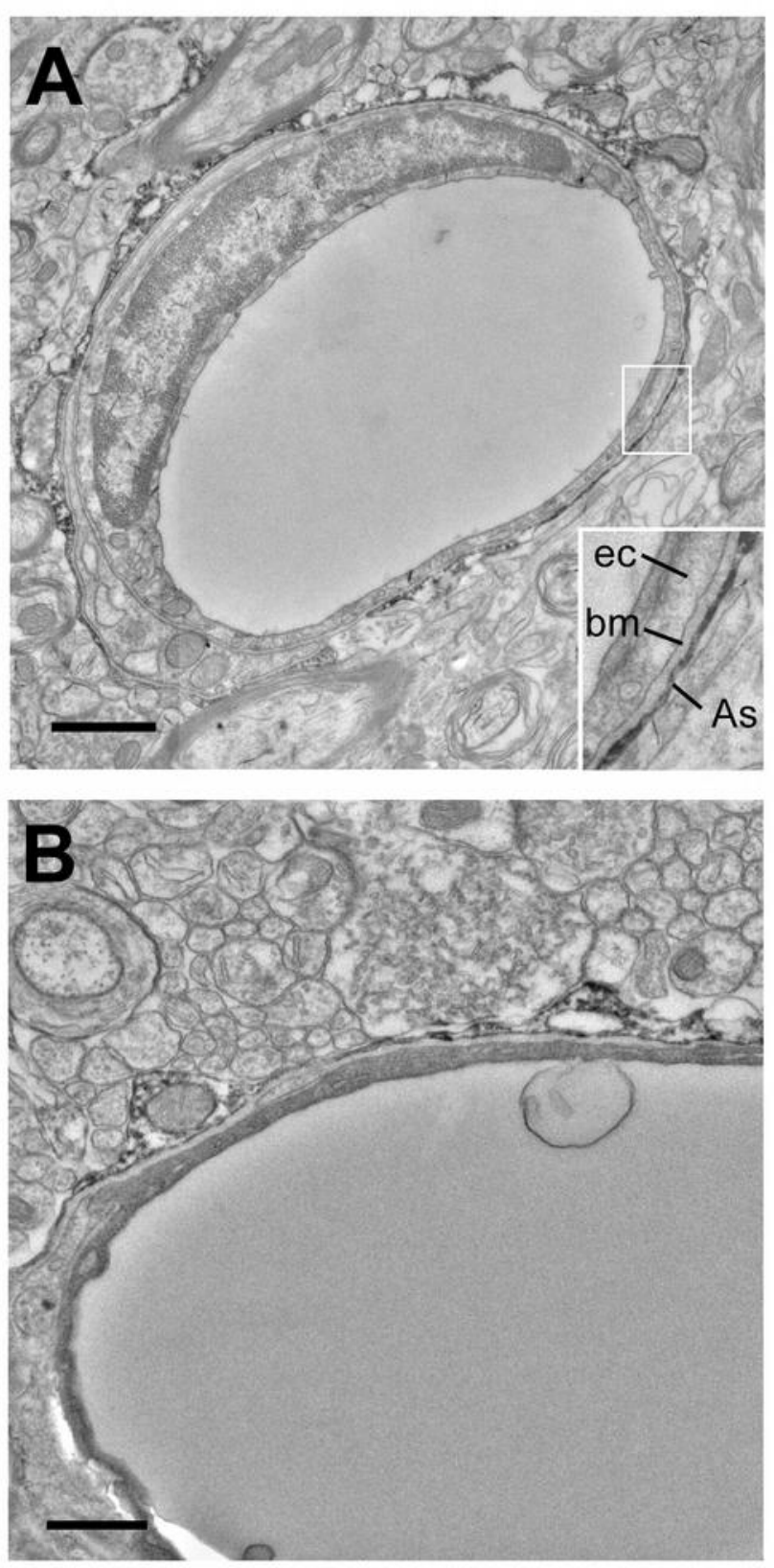

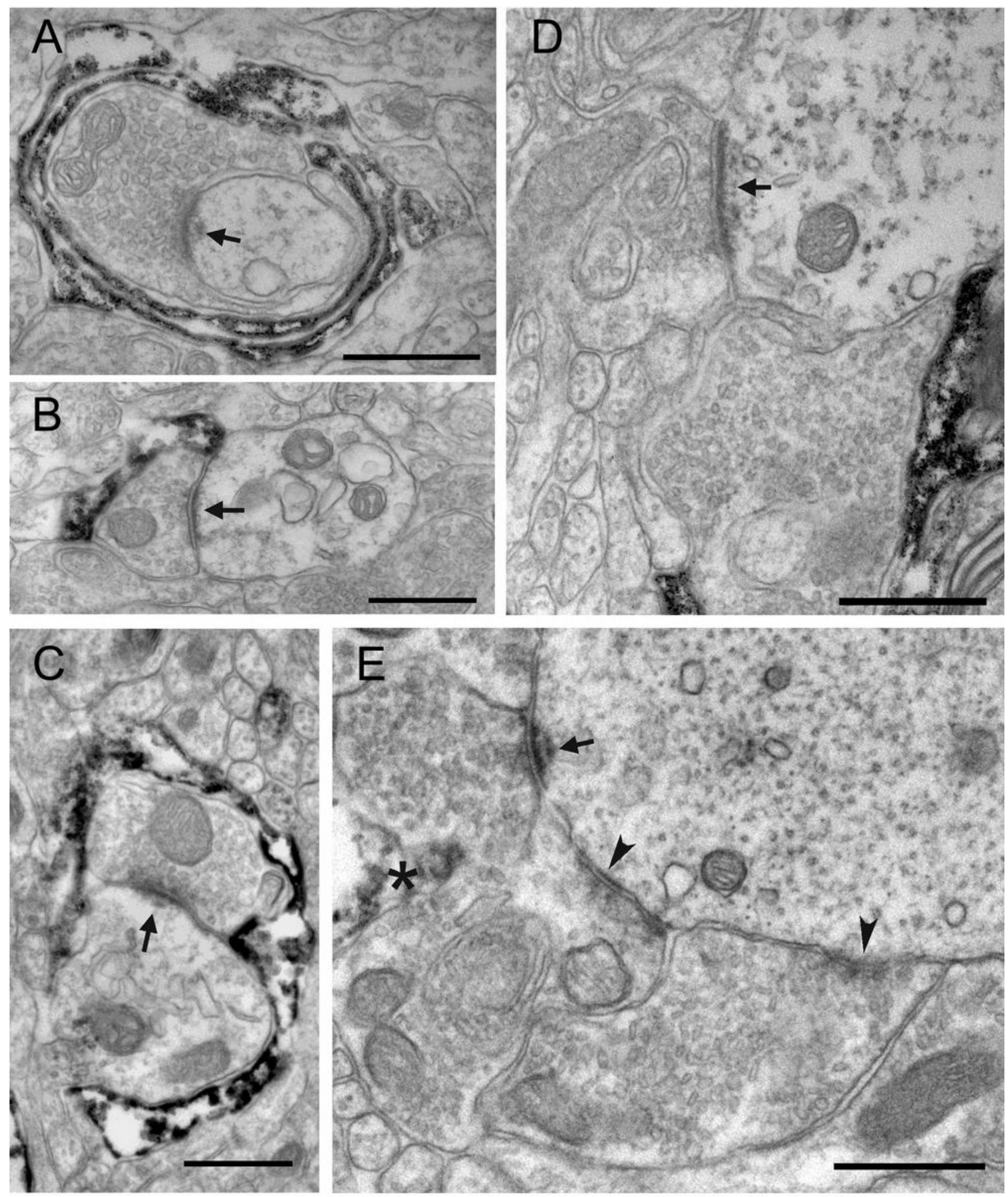

Figure 4 
A

Axonal bouton
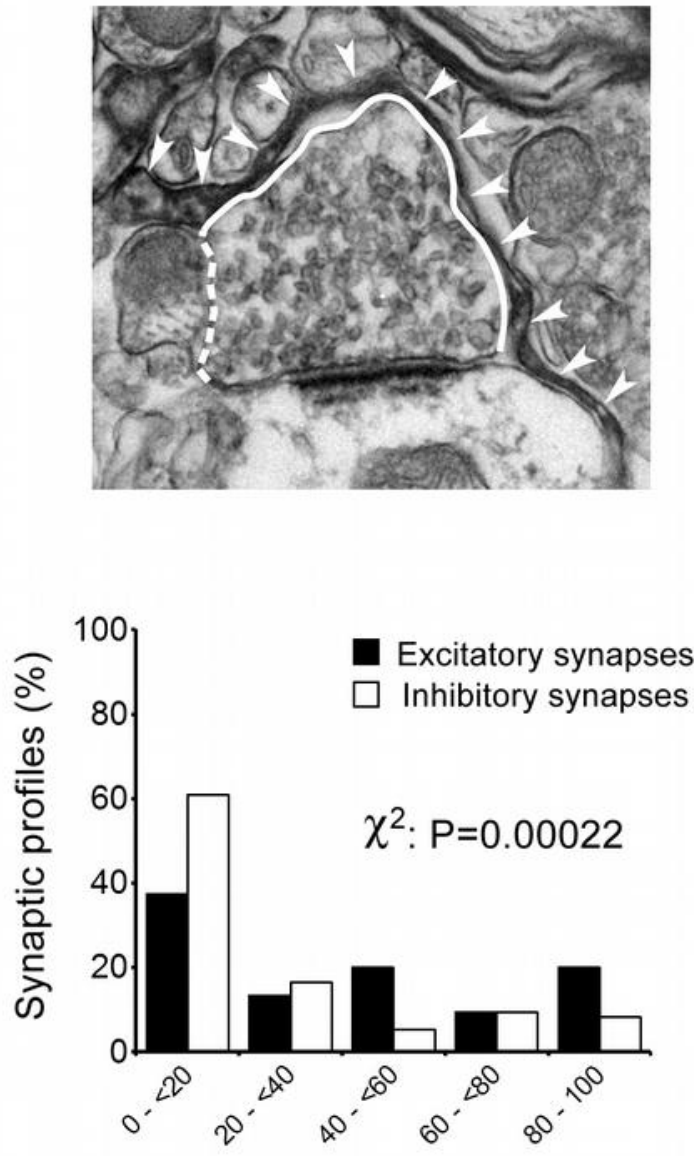

Glial coverage (\%)
B Axon-dendrite interface (ADI)

0

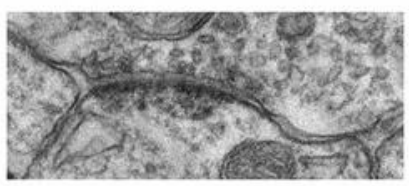

1

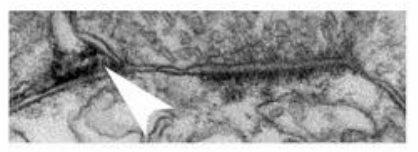

2

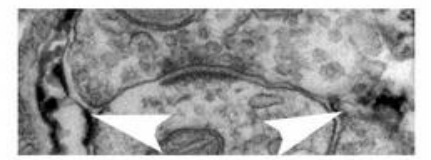

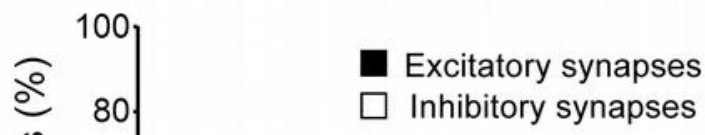

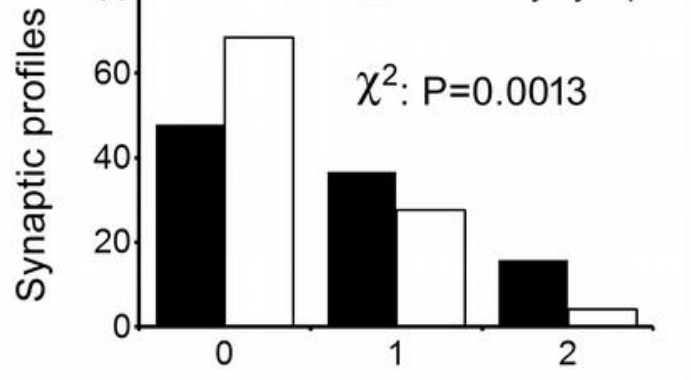

Glial occurrences at $A D I$ edges

Figure 5 

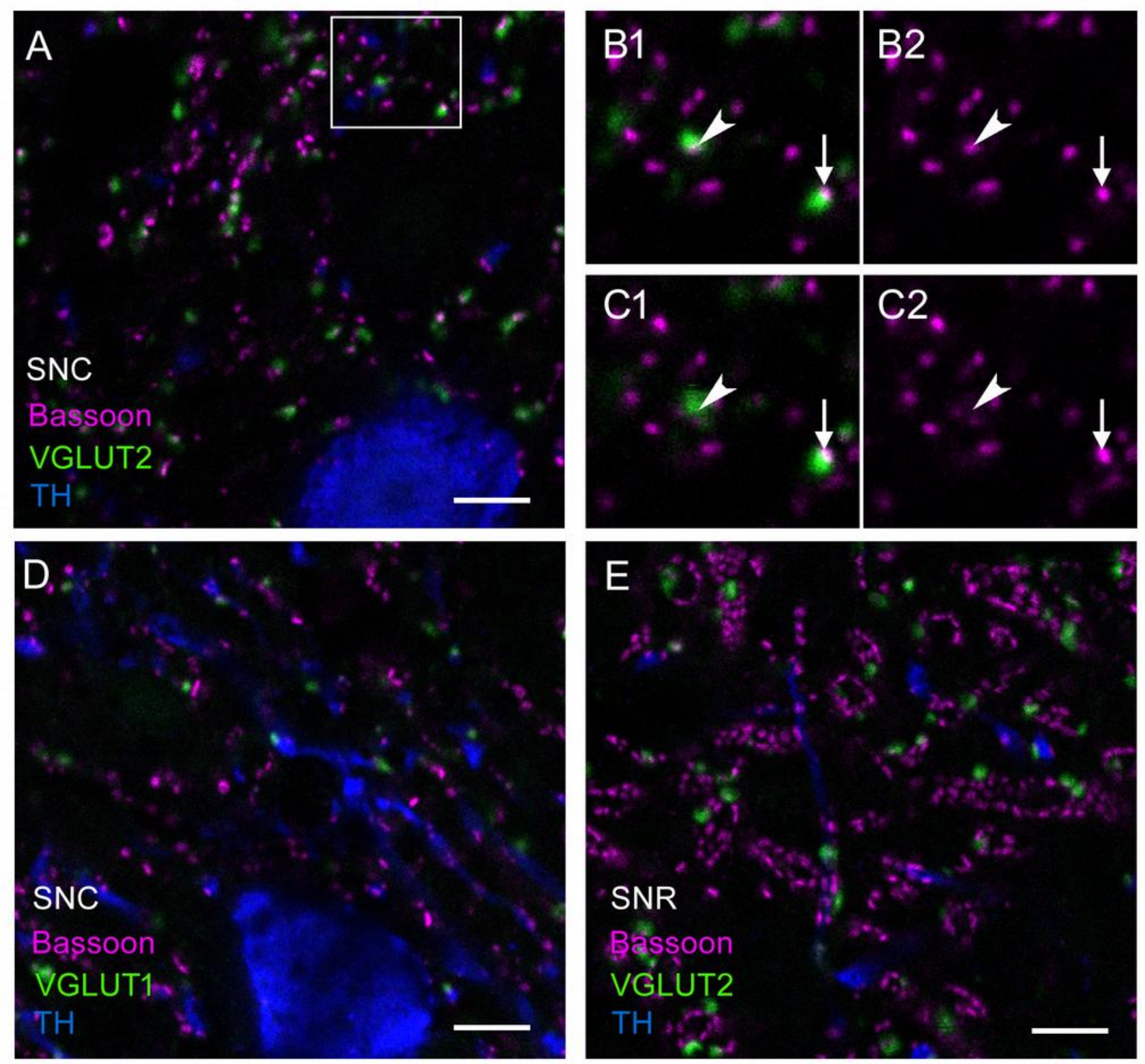

Figure 6 